\title{
Cadherin and catenin biology represent a global mechanism for epithelial cancer progression
}

\author{
Janusz A Jankowski, Rachel Bruton, Neil Shepherd, D Scott A Sanders
}

\begin{abstract}
The cell undergoes a diverse range of stimulations including growth factor activation and signal transduction from adhesion receptors, such as cadherins. In the absence of a mitogenic signal from outside the cell, $\beta$ catenin is sequestered in complexes with the product of the adenomatous polyposis coli (APC) gene and a

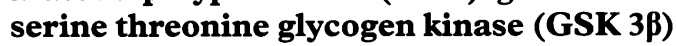
enabling degradation of free $\beta$ catenin. Residual catenins hold cells together by binding to cadherins both at adherens junctions and the actin cytoskeleton. When a mitotic signal is delivered by the wnt pathway, GSK $3 \beta$ is antagonised so that $\beta$ catenin can no longer be degraded. Cytosolic concentrations rise and binding to other newly synthesised proteins occurs, especially transcription factors that are transported to the nucleus, such as lymphocyte enhancing factor and $T$ cell factor. This article discusses the signalling between mitogenic and adhesion pathways and suggests that it is a global mechanism for development, differentiation, and disease. These changes in catenin and APC biology may not be sufficient alone to transform cells fully but they appear to be a necessary final common pathway for several cancers of the mucous secreting crypts (including Barrett's oesophageal lesions and colorectal cancer) or stratified secreting epithelium (melanoma) before invasion.
\end{abstract}

(F Clin Pathol: Mol Pathol 1997;50:289-290)

Keywords: adenomatous polyposis coli; cadherins; cancer; catenins; colon; oesophagus; transcription

Epithelial tissues are constantly adapting to physiological stimuli in the surrounding environment by proliferation, differentiation, apoptosis, and cell migration. ${ }^{1}$ These processes are pre-programmed temporally in the genome but they are also under the influence of several signal transduction pathways initiated by contact with adjacent cells in the immediate microenvironment. In particular, the cell is under diverse stimuli including growth factor activation and signal transduction from adhesion receptors, such as cadherins. Perturbation of the balance between these mechanisms may play a role in early tumorigenesis and one of the key molecules involved in modulating this process is $\beta$ catenin. ${ }^{2-4}$ In particular, $\beta$ catenin modulation may explain how mutations of the adenomatous polyposis coli (APC) gene initiate the formation of adenomas that can develop into fatal carcinomas.

In the absence of a mitogenic signal from outside the cell, $\beta$ catenin is sequestered in complexes with the APC gene product and a serine threonine glycogen kinase (GSK $3 \beta$ ), enabling degradation of free $\beta$ catenin. ${ }^{2-6}$ Residual catenins hold cells together by binding to cadherins both at adherens junctions and the actin cytoskeleton (fig 1). When a mitotic signal is delivered by the wnt pathway, GSK $3 \beta$ is antagonised so that $\beta$ catenin can no longer be degraded. Cytosolic concentrations rise and binding to other newly synthesised proteins occurs, especially transcription factors that are transported to the nucleus, such as lymphocyte enhancing factor (LEF) and $T$ cell factor (Tcf-4).

These interacting signalling pathways are important in embryogenesis, especially epithelio-mesenchymal transition, and in epithelial tumorigenesis. In this regard, the wnt-1 gene product is required for normal development of the mammalian central nervous system but can also contribute to mammary oncogenesis when expressed inappropriately in the mammary gland or in cell lines in vitro. ${ }^{7}$ Furthermore, work on Xenopus laevis and Drosophila melanogaster embryos provided new insights, as early as the gastrulation stage of development. $^{8} \beta$ catenin in the nucleus binds either to LEF-1 or Tcf-4 transcription factors and acts as a cofactor to regulate the transcription of genes, thereby allowing catenin regulated transcription.

It is now known that this residual free monomeric $\beta$ catenin binds to the high mobility group domain (HMG) of the two transcription

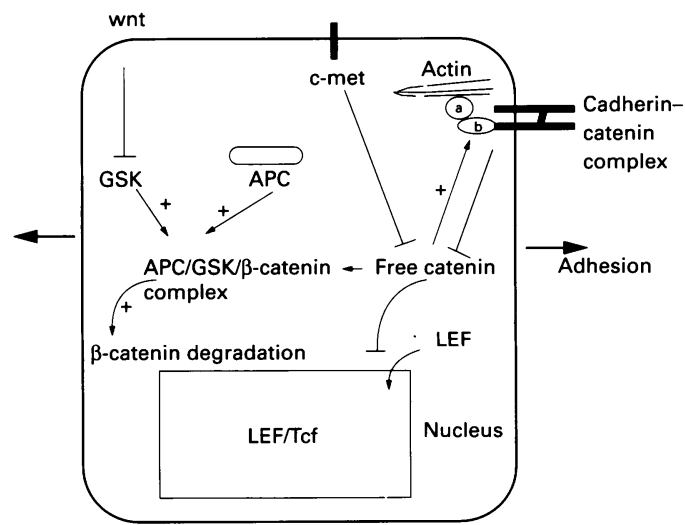

Figure 1 Regulation of adhesion in non-transformed cells. In the absence of wnt-1, GSK $3 \beta$ is active and together with wild-type APC binds to the free $\beta$ catenin resulting in degradation. The catenins in the cadherin complexes are bound tightly in the adherens junctions providing polarised non-motile cells (+ indicates stimulation of the pathway). 


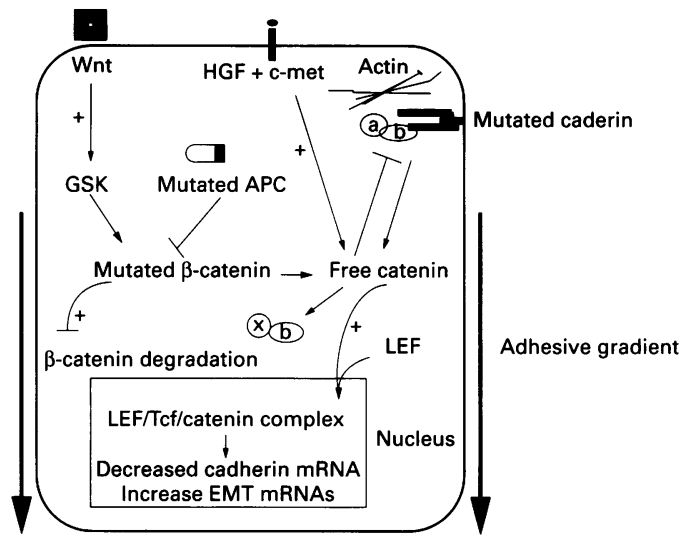

Figure 2 Regulation of adhesion in transformed cells. In the presence of wnt-1, GSK $3 \beta$ is inactivated and mutant $A P C$ or tyrosine phosphorylated $\beta$ catenin cannot bind each other, resulting in an excess of free (monomeric) $\beta$ catenin. Monomeric $\beta$ catenin can still bind various proteins in the cytosol $(x)$ including $L E F / T$ cf and together they act as cofactors for transcription of genes including negative regulation of $E$ cadherin expression and positive regulation of epithelio-mesenchymal transition (EMT) resulting in invasion (+ indicates stimulation of the pathway).

factors, Tcf-4 and LEF, although interaction with other Tcf family members has yet to be proven. The HMG domain can bind in a sequence specific manner to the promoters of target genes and, in combination with $\beta$ catenin, which acts as a cofactor, individual promoters can be activated or suppressed resulting in epithelio-mesenchymal transition. The $\mathrm{E}$ cadherin promoter is regulated negatively by this complex and, consequently, transcription, cell-cell adhesion, and probably contact inhibition is weakened leading, in part, to invasion (fig 2). ${ }^{10}$ It is interesting to observe that several candidate genes implicated in progression are upregulated during catenin regulated transcription.

It is now believed that transformation of adult mammalian cells into malignant tumours may reflect an exaggeration of this process. The APC gene product is mutated early in many cancers leading to reduced $\beta$ catenin degradation and, hence, an increased risk of aggregating with transcription factors. Moreover, in epithelial cancers, $\beta$ catenin may also undergo aberrant phosphorylation, owing to mutations in the coding sequences of serine residues, resulting in the substitution of serine with tyrosine or other residues. ${ }^{3-6}$ GSK $3 \beta$ activity requires the presence of multiple serine residues at the binding recognition sites of its substrates, including $\beta$ and $\gamma$. These $\beta$ catenin mutations have a dominant effect, suppressing the APC dependent binding and degradation of even wild-type $\beta$ catenin. ${ }^{10}$ Moreover, to complicate matters further, activation of several receptor tyrosine kinases, including receptors for hepatocyte growth factor (Met) and epidermal growth factor, are commonly increased during cancer; this results in the hyperphosphorylation of tyrosine on $\beta$ catenin and $\gamma$ catenin, making them unable to bind cadherin. ${ }^{11}$
This model is compelling because it also explains the apparent differences between certain APC mutations, especially those with mutations of the catenin binding domains, $₹$ which are associated with the most aggressive 으 cell phenotype. The phenotype and invasive potential of these transformed cells can be influenced further by destabilisation of the $\overrightarrow{\bar{F}}$ adherens junctions, such as occurs commonly $\frac{0}{2}$ as a result of cadherin mutation. Moreover, it supports the current theory that invasion not only requires a transformed genotype involving Ki-ras mutations, p53 mutations, bcl-2 overexpression, and microsatellite or chromosomal instability, ${ }^{12}{ }^{13}$ but also loss of inhibitory environmental cues from the crypt microenvironment, such as altered adhesion and mitogenesis.

These changes in catenin and APC biology 0 may not transform cells fully but they appear to be a necessary final common pathway for several cancers of the mucous secreting crypts (colorectal cancer) or melanoma before inva- 9 sion. The assessment of catenin or APC muta- $\vec{\square}$ tions in surveillance programmes represents an important tool by which to stratify risk in patients at risk for cancer.

In conclusion, small differences in specific combination, concentrations, function, and distribution of catenins (and cadherins) are present in each cell type and can dictate a specific "embryonic" or cancer phenotype. ${ }^{14}$

1 Jankowski J, Wright N. Epithelial stem cells in gastrointestinal morphogenesis, adaptation and carcinogenesis. Sem Cell Biol 1992;3:445-56.

2 Korinek V, Barker N, Morin PJ, van Wichen D, de Weger R, Kinzler $\mathrm{K}$, et al. Constitutive transcriptional activation by a $\beta$ catenin-Tcf complex in APC-/- colon carcinoma. Science 1997;275:1784-7.

3 Morin PJ, Sparks AB, Korinek V, Barker N, Clevers H, Vogelstein B, et al. Activation of $\beta$-catenin-Tcf signaling in colon cancer by mutations in $\beta$-catenin or APC. Science 1997;275:1787-90.

4 Rubinfeld B, Robbins P, El-Gamil M, Albert I, Porfiri E, Polakis P. Stabilisation of $\beta$-catenin genetic defects in 8 melanoma cell lines. Science 1997;275:1790-2.

5 Papkoff J, Rubinfeld B, Schryver B, Polakis P. Wnt-1 regulates free pools of catenins and stabilizes APC-catenin complexes. Mol Cell Biol 1996;16:2128-34.

6 Rubinfeld B, Souza B, Albert I, Muller O, Chamberlain SC, Masiarz F, et al. Association of the APC gene product with $\beta$-catenin. Science 1993;262:1731-4.

7 Hinck L, Nelson WJ, Papkoff J. Wnt-1 modulates cell-cell 5 adhesion in mammalian cells by stabilising $\beta$-catenin bind- $N$ ing to the cell adhesion protein cadherin. $\mathcal{F}$ Cell Biol 1994; 124:729-41.

8 Behrens J, Mareel MM, Kuhl M, Bruhn L, Wedlich D, Grosshedi $R$, et al. Functional interaction of $\beta$-catenin with the transcription factor LEF-1. Nature 1996;382:638-42.

9 Vleminckx K, Vakaet L, Mareel M, Fiers W, Van Roy F. Genetic manipulation of E-cadherin expression by epithelial tumour cells reveals an invasion suppressor role. Cell 1991;66:107-19.

10 Welsh GI, Wilson C, Proud CG. GSK3: a shaggy frog story. Trends Cell Biol 1996;6:274-9.

11 Hoschuetzky $\mathrm{H}$, Aberle $\mathrm{H}$, Kemler R. $\beta$-catenin mediates the interaction of the cadherin-catenin complex with epidermal growth factor receptor. $f$ Cell Biol 1994;127: ర 1375-80.

12 Fearon E, Vogelstein B. A genetic model for colorectal tumorigenesis. Cell 1990;61:759-67.

13 Lengauer C, Kinzler K, Vogelstein B. Genetic instability in colorectal cancers. Nature 1997;386:623-6.

14 Jankowski J, Bedford FK, Kim YS. Changes in cadherin gene structure and regulation during epithelial development, differentiation and disease. Nucleic Acids Res Mol Biol 1997;57:187-215. 